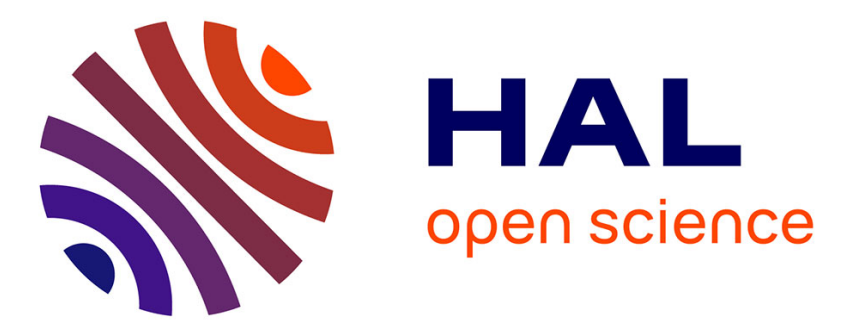

\title{
Comparison of e-cigarette use characteristics between exclusive e-cigarette users and dual e-cigarette and conventional cigarette users: an on-line survey in France
} Ivan Berlin, Bertrand Nalpas, Rémi Targhetta, Pascal Perney

\section{- To cite this version:}

Ivan Berlin, Bertrand Nalpas, Rémi Targhetta, Pascal Perney. Comparison of e-cigarette use characteristics between exclusive e-cigarette users and dual e-cigarette and conventional cigarette users: an on-line survey in France. Addiction, 2019, 114 (12), pp.2247-2251. 10.1111/add.14780 . hal02860061

\section{HAL Id: hal-02860061 https://hal.science/hal-02860061}

Submitted on 16 Oct 2020

HAL is a multi-disciplinary open access archive for the deposit and dissemination of scientific research documents, whether they are published or not. The documents may come from teaching and research institutions in France or abroad, or from public or private research centers.
L'archive ouverte pluridisciplinaire HAL, est destinée au dépôt et à la diffusion de documents scientifiques de niveau recherche, publiés ou non, émanant des établissements d'enseignement et de recherche français ou étrangers, des laboratoires publics ou privés. 


\title{
Comparison of e-cigarette use characteristics between exclusive e-cigarette users and dual e-cigarette and conventional cigarette users: an online survey in France
}

\author{
Running head: Dual users of electronic cigarettes
}

Ivan Berlin ${ }^{1}$, Bertrand Nalpas ${ }^{2,3}$, Rémi Targhetta ${ }^{2}$, Pascal Perney ${ }^{2,3,4}$,

${ }^{1}$ Hôpital Pitié-Salpêtrière, Département de pharmacologie, Paris, France and Centre Universitaire de Médecine Générale et de Santé Publique, Lausanne, Switzerland

${ }^{2}$ Service d'Addictologie, Centre Hospitalier Universitaire Caremeau, Nîmes, France

${ }^{3}$ Département d'Information Scientifique et Communication, Inserm, Paris, France

${ }^{3}$ Université Montpellier I, Montpellier, France

${ }^{4}$ Inserm U1178, Paris, France

Running title: Distinction between exclusive electronic cigarette users and dual users

Word count

Main text: 1983 ; abstract: 268 ; number of references: 21

Number of tables: 2

Corresponding author:

Ivan Berlin, Hôpital Pitié-Salpêtrière, Département de pharmacologie, 47-83 bd de l'Hôpital, 75013 Paris, France

Email : ivan.berlin@aphp.fr

Telephone: +33142161678

Conflict of interest statement. None of the authors report conflict of interest with respect to this manuscript. I. Berlin reports occasional honoraria for presentations and participation in an advisory board for Pfizer in the last 3 years. 


\begin{abstract}
Background and aims: Completely substituting e-cigarettes (EC) for combustible tobacco cigarettes reduces exposure to toxicants and carcinogens. However, a large proportion of EC users (dual users) continue to smoke conventional cigarettes. This study aimed to compare estimated nicotine intake and e-cigarette use characteristics between exclusive EC users and dual users.
\end{abstract}

Design: Web-based anonymous cross-sectional survey.

Setting: France.

Participants: 3189 adults, current users of electronic cigarettes (EC). Data collection between 4 October 2014 and 11 November 2014.

Measurements: Primary outcome: estimated nicotine intake per day (mg) from participants' reports. Secondary outcomes: duration, frequency of EC use, and nicotine content of e-liquids used/day. Dual use was defined as using at least one cigarette per day while using also EC.

Findings: 2836 respondents reported exclusive EC use and 353 reported being dual users. Backward stepwise logistic regression showed that dual users had higher estimated daily nicotine intake from e-liquids and cigarettes [estimate: 2.14 SE: 0.26, adjusted odds ratio (aOR): $8.48,95 \%$ confidence interval $(\mathrm{CI})=5.11$ to $14.09, \mathrm{P}<0.001]$, but lower daily nicotine intake from EC [estimate: -2.14, SE: 026, aOR: 0.12, CI=0.07 to 0.196, P<0.001] and reported less months of EC use [estimate -0.31, SE: 0.14, aOR: 0.73, CI=0.56 to 0.95, $\mathrm{P}=0.022]$ compared with exclusive EC users.

Conclusion: Dual e-cigarette users in France may have higher nicotine intake overall than exclusive e-cigarette users but they may take in less nicotine from their e-cigarettes.

Key words: electronic cigarette only users, dual users, nicotine intake from electronic cigarette 


\section{Introduction}

Electronic cigarettes (EC) are diverse battery-powered devices that produce an aerosol. The battery heats a resistance that allows aerosolisation of the liquid called "e-liquid" which contains humectants (propylene glycol and/or glycerin) along with flavorants and may or may not contain nicotine. The European Union Tobacco Product Directive of April 2014 limited the nicotine content of EC to $20 \mathrm{mg} / \mathrm{mL}$ [1]. As of today, in France, ECs are consumer products and sold outside the health care system. It is usually believed that EC help smokers quit smoking; however, observational cohorts have provided conflicting results as an aid to quitting smoking $[2,3,4]$ and two randomized studies with early EC did not show a therapeutic efficacy in smoking cessation [5,6]. In the most recently published pragmatical trial the one-year abstinence rate was $18 \%$ among those randomised to receive EC and $9.9 \%$ among those randomised to receive nicotine replacement therapy, a difference statistically significant [7]. A highly exhaustive report concluded that "There is conclusive evidence that completely substituting e-cigarettes for combustible tobacco cigarettes reduces users' exposure to numerous toxicants and carcinogens present in combustible tobacco cigarettes" $[8]$.

In 2016, $58.8 \%$ of vapers were dual users in France [9], and $63.9 \%$ in New Zealand [10], a prevalence similar to that observed in the USA in 2015 (59\%) [11]. According to recent data, dual use is $44 \%$ of vapers in the UK [12].

The individual need of daily nicotine dose is highly variable among smokers; furthermore, individual dose titration of nicotine replacement therapies according to withdrawal symptoms provides similar results to achieve smoking cessation than dose titration according to saliva cotinine [13]. A recent study suggests that progressive nicotine patch up-titration improves cessation rate (14). It is therefore likely that dual users, while reducing their usual cigarette 
consumption, remain dual users because their individual nicotine substitution rate is less than needed. The aims of this study were to: (a) estimate the strength of association between demographics, smoking history and EC use characteristics among exclusive EC users and dual users; b) compare characteristics of dual use to exclusive EC use.

\section{Methods}

Design. A cross-sectional survey was launched to assess the association of demographic, smoking and EC characteristics among current EC users. Individuals who currently used EC (vapers) were eligible and asked to participate in this French language survey.

Participants/Procedures. On October $4^{\text {th }}, 2014$, an advertisement was posted in a local daily newspaper, on its website, on the TV channel "France 3", and on a the Facebook wall page explaining that a survey aiming to evaluate the characteristics of EC use on tobacco consumption was to be conducted on-line during the following month. Repeat advertisements were posted two weeks later in the same media outlets. The survey ran from October 4th to November 11th, 2014. The questionnaire was managed and hosted by a company dedicated to on-line surveys (www.sondageonline.com®). An integrated control checked IP addresses and did not authorize two answers from the same computer. When the survey was conceived, very little was known about EC and in particular about the nicotine amount in EC between exclusive vapers and dual users. Because this lack of previous data, power calculation could not be undertaken. It was simply stated in the survey's protocol that at least 1000 responders would be needed to make some meaningful conclusions.

\section{Measures.}

\section{Key predictors}

Nicotine consumption by e-liquids was calculated as follows: "How much e-liquid do you vape per day?" Answers: 0 to $\leq 2 \mathrm{~mL} ; 2$ to $\leq 4 \mathrm{~mL} ; 4$ to $\leq 6 \mathrm{~mL}$; more than $6 \mathrm{~mL}$ The question as to the nicotine strength was : "Do you use currently an e-liquid only without nicotine? Or only with nicotine?" For this second question the answers were as follows: 1 to 6 $\mathrm{mg} ; 8$ to $12 \mathrm{mg}$; 16 to $19 \mathrm{mg}$. These categories followed the strengths available in $2014 \mathrm{in}$ the e-liquid market. We used the formula proposed by Goniewicz et al. [15]: e-liquid nicotine concentration $(\mathrm{mg} / \mathrm{mL}) \times$ amount of e-liquid used/day $(\mathrm{mL}) \times$ percent of nicotine vaporized. 
We considered, according to Goniewicz et al. [15], that $60 \%$ of nicotine from a cartridge was aerosolized. When the responder could not provide the amount of e-liquid he/she used per day, he/she could report how long a vial's use could last; thus, we divided the vial volume by the number of days of use. It is notable that in 2011, that is before the study was run, the French national medication agency (Agence nationale de sécurité du médicament (ANSM)) stated that the nicotine content for individual cartredges cannot be higher than $10 \mathrm{mg}$ and for refill vials should be less or equal to $20 \mathrm{mg} / \mathrm{mL}$ [16].

\section{Covariates.}

Age, sex, daily tobacco consumption, previous tobacco use history, duration of vaping, its frequency, the nicotine concentration, and the quantity of e-liquid used per day were recorded. Previous quit attempts referred to smoking prior EC use. A question about checking for his/her EC when leaving was added as a control variable. This question, as a measure of adherence to EC use, was included since one of the simplest reasons not to use EC is having forgotten it at home when leaving. EC make/type was not recorded because of the large number of available models. Dependence on EC was measured by the modified Fagerström Test for Cigarette Dependence (FTCD) [17] replacing questions about cigarettes by "vaping" and number of cigarettes by amount of e-liquid used. As with FTCD, we created a total score that could range from 0 to 10 . The frequency of EC use was assessed by the question: "How frequently do you vape ?" The answer was conditional. The first level was: «not every day »

OR « everyday ». If « everyday » was selected, then the participant had to choose between "not very often", “often", "very often". Nicotine consumption through cigarette smoking was assessed by multiplying the cigarettes/day by $1 \mathrm{mg}$, considered as an acceptable approximation of the nicotine amount delivered by a cigarette $[15,18]$.

Ethics. Because this was an anonymous survey, according to French law, approval from an ethics committee was not required. However, the aims and the methodology of the survey were explained on the home page of the survey and participants provided informed consent before completing the survey.

Data analysis. Data for continuous variables are presented as means and standard deviations; frequencies by numbers and percent. Exploratory analysis by ANOVA was used for univariate comparisons. Stepwise descendent logistic regression (Wald's method) was used to test the variables' association with groups. Variables with a $\mathrm{p}$ value $\leq 0.01$ in the univariate analyses were included in the regression model. In the final regression model only variables 
with a $p$ value of $\leq 0.05$ were considered as significantly associated with the type of EC users. All analyses were run using SPSS V22 software (IBM SPSS Inc, Armonk, NY, USA).

\section{Results}

Among the 3189 responders, 2836 reported exclusive EC use and 353 (11\%) reported dual use. Among the exclusive vapers 1634 (58 \%) reported having stopped conventional cigarettes "the day I started using EC"; 61 (2\%) reported being free of tobacco when starting EC and 1138 (40\%) after having started EC. Thus, individuals of this latter group, exclusive vapers, at the time of the survey were previously dual users at some point.

All recorded variables showed significant differences between the two groups of vapers (Table 1). There were more women among dual users than among exclusive vapers. Dual users were younger, reported more previous quit attempts and checked more frequently if their EC was with them when leaving home; used somewhat more nicotine in e-liquids but vaped for a shorter period than exclusive vapers. The modified Fagerström Test for EC total score was higher among exclusive vapers probably because they reported more e-liquid use (exclusive vapers: 3.0 (1.9), 3.4 (1.7), 3.6 (1.9); dual users: 2.4 (1.1), 2.8 (1.3), 3.2 (1.4) mL during the first 6 months, 6 to 12 months and more than 12 months of vaping, respectively, $\mathrm{p}<0.001)$. Shorter time to first EC use after awakening was more frequent among dual users than among EC only users: $\leq 5$ min.: 13.3 vs $7.9 \%$; 6 to 30 min.: 20.4 vs $19 \%$; 31 to 60 min.: 41.6 vs $38 \%>60$ min.: 30.2 vs $29.7 \%$, $\mathrm{p}=0.007$ ). We calculated that dual users reported taking 11.7 (9.6) $\mathrm{mg}$ nicotine from conventional cigarettes along with vaping leading to a higher total nicotine intake in dual users compared with exclusive vapers.

Stepwise backward elimination logistic regression showed that only three variables differentiated dual users from exclusive vapers. Dual users reported a shorter duration of vaping than exclusive vapers; they had higher daily total nicotine intake but lower nicotine intake from EC. Compared to the univariate comparison, the direction of this latter association was reversed by adjustment for variables included in the model (Table 2). Replacement of the total score of the Fagerström Test for EC dependence by time to first EC use did not change these results.

\section{Discussion}

In this Internet sample of 3189 vapers, most of the vapers (89\%) reported exclusive use of EC. Multivariable logistic regression showed that although dual users use less nicotine from 
e-liquids they concurrently smoke probably in order to satisfy their nicotine need by getting nicotine from conventional cigarettes. It is likely that dual users are more highly nicotine dependent than exclusive EC users. In line with this is the finding that they reported using EC earlier after awakening than exclusive vapers. Moreover, dual users reported shorter duration of EC use. These results may suggest that dual users should increase their nicotine substitution dose from e-liquid to suppress their need to smoke also conventional cigarettes. It is also likely that dual users can suppress smoking conventional cigarettes if they use EC for a longer period.

To the best of our knowledge, only one paper compared dual users and EC only users in terms of characteristics and consumption [19]. Questionnaires were completed in nine vape shops in Louisville, Kentucky (67 EC only users, 11 dual users). Exclusive EC users consumed higher levels of nicotine in e-liquids and more nicotine per month. Dual users started EC earlier after awakening than EC only users. The current survey, with a larger sample size shows similar results.

Daily use of EC while smoking is associated with increased number of cessation attempts but not with successful cessation [20]. Dual use can be understood as insufficient nicotine intake from EC by individuals who intend to stop conventional cigarette smoking. Dual use does not seem to improve the likelihood of quitting tobacco and some dual users return to smoking [21]. On the other hand, switching from dual use to exclusive EC use by increasing nicotine intake from EC may result in quitting conventional cigarettes.

\section{Strength and Limitations}

The strength of this survey is the large sample size. Limitations include: cross sectional, observational study based on self-reports; lack of biochemical verification of self-report of not smoking conventional cigarettes; and unknown level of intention to quit conventional cigarettes. Although in 2014, all EC devices were performing less well in terms of nicotine delivery, it cannot be excluded that more dual users used low nicotine delivery devices. The data were collected in 2014 and may not therefore be representative of current usage patterns. Non-recording of potential confounders as is always the case in non-randomized studies could also have contributed to the observed findings. It cannot be excluded that successful quitters of conventional cigarettes that is exclusive EC users were more likely to complete the survey than dual users leading to a selection bias. 


\section{Conclusions}

The current results suggest that dual users take up insufficient amount of nicotine from EC than needed and use EC for a shorter period than exclusive EC user former smokers. Dual users should be encouraged to self-titrate their daily nicotine intake until no conventional cigarette is needed. Further prospective studies should confirm the current findings.

\section{References}

1. Official Journal of the European Union. Directive 2014/40/EU of the European Parliament and of the council of 3 April 2014.

http://ec.europa.eu/health//sites/health/files/tobacco/docs/dir_201440_en.pdf. Accessed on 10 September 2018.

2. El Dib R, Suzumura EA, Akl EA, Gomaa H, Agarwal A, Chang Y, Prasad M, Ashoorion V, Heels-Ansdell D, Maziak W, Guyatt G. Electronic nicotine delivery systems and/or electronic non-nicotine delivery systems for tobacco smoking cessation or reduction: a systematic review and meta-analysis. BMJ Open 2017; 7(2):e012680. doi: 10.1136/bmjopen2016-012680.

3. Kalkhoran S, Glantz SA. E-cigarettes and smoking cessation in real-world and clinical settings: a systematic review and meta-analysis. Lancet Respir Med. 2016; 4(2):116-28. doi: $10.1016 / \mathrm{S} 2213-2600(15) 00521-4$.

4. Weaver SR, Huang J, Pechacek TF, Heath JW, Ashley DL, Eriksen MP. Are electronic nicotine delivery systems helping cigarette smokers quit? Evidence from a prospective cohort study of U.S. adult smokers, 2015-2016. PLoS One. 2018; 13(7):e0198047. doi: 10.1371/journal.pone.0198047.

5. Bullen C, Howe C, Laugesen M, McRobbie H, Parag V, Williman J, Walker N. Electronic cigarettes for smoking cessation: a randomised controlled trial. Lancet. 2013; 382(9905): 1629-37.

6. Caponnetto P, Campagna D, Cibella F, Morjaria JB, Caruso M, Russo C, Polosa R. Efficiency and Safety of an electronic cigarette (ECLAT) as tobacco cigarettes substitute: a prospective 12-month randomized control design study. PLoS One 2013; 8(6):e66317.

7. Hajek P, Phillips-Waller A, Przulj D, Pesola F, Myers Smith K, Bisal N, Li J, Parrott S, Sasieni P, Dawkins L, Ross L, Goniewicz M, Wu Q, McRobbie HJ. A Randomized Trial of E-Cigarettes versus Nicotine-Replacement Therapy.N Engl J Med. 2019 Feb 14;380(7):629637. doi: 10.1056/NEJMoa1808779.

8.The National Academies of Sciences, Engineering, Medicine 2018. Public health consequences of e-cigarettes. January 23, 2018.

http://nationalacademies.org/hmd/reports/2018/public-health-consequences-of-ecigarettes.aspx Accessed December 31, 2018. 
9. Pasquereau A, Gautier A, Andler R, Guignard R, Richard JB, Nguyen-Thanh V. Tabac et e-cigarette en France : niveaux d'usage d'après les premiers

résultats du Baromètre santé 2016. Bull Epidémiol Hebd. 2017; 12:214-22. http://invs.santepubliquefrance.fr/beh/ 2017/12/2017_12_1.html. Accessed on December 31, 2018.

10. Oakly A, Martin G. Dual use of electronic cigarettes and tobacco in New Zealand from a nationally representative sample. Aust N Z J Public Health. 2019 Apr;43(2):103-107. doi: $10.1111 / 1753-6405.12871$

11. Centers for Disease Control and Prevention (2016) QuickStats: cigarette smoking status among current adult e-cigarettes users by age group-National Health Interview Survey, United States, 2015. https://www.cdc.gov/ mmwr/volumes/65/wr/mm6542a7.htm. Assessed on January 1, 2019.

12. Action of smoking and helath (ASH). Use of e-cigarettes (vapourisers) among adults in Great Britain. September 2018.

file:///D:/users/500416/Downloads/ASH-Use-of-E-cigarettes-by-adults-in-Great-Britain-

2018.pdf Accessed on Jun 25, 2019

13. Berlin I, Jacob N, Coudert M, Perriot J, Schultz L, Rodon N. Adjustment of nicotine replacement therapies according to saliva cotinine concentration: the ADONIS* trial-a randomized study in smokers with medical comorbidities. Addiction 2011; 106(4):833-43. doi: 10.1111/j.1360-0443.2010.03306.x.

14. Przulj D, Wehbe L, McRobbie H, Hajek P. Progressive nicotine patch dosing prior to quitting smoking: feasibility, safety and effects during the pre-quit and post-quit periods.

Addiction. 2019;114(3):515-522. doi: 10.1111/add.14483. Epub 2018 Dec 11.

15. Goniewicz, M.L., Kuma, T., Gawron, M., Knysak, J., Kosmider, L. Nicotine levels in electronic cigarettes. Nicotine Tob Res 2013; 15: 158-66. doi: 10.1093/ntr/nts103

16. Direction générale de la concurrence, de la consommation et de la répression des fraudes. Cigarette électronique.

https://www.economie.gouv.fr/dgccrf/Publications/Vie-pratique/Fiches-pratiques/cigaretteelectronique

17. Fagerström K. Determinants of tobacco use and renaming the FTND to the Fagerstrom Test for Cigarette Dependence. Nicotine Tob Res. 2012; 14(1):75-78.

18. Benowitz NL, Jacob P. 3rd. Daily intake of nicotine during cigarette smoking. Clin Pharmacol Ther 1984; 35: 499-504.

19. Lee S, Hart JL, Walker KL, Keith RJ, Ridner S. Dual users and electronic cigarette only users: Consumption and characteristics. Int J Health Med Sci 2018; 4(6) 111-6. 
20. Brose LS, Hitchman SC, Brown J, West R, McNeill A. Is the use of electronic cigarettes while smoking associated with smoking cessation attempts, cessation and reduced cigarette consumption? A survey with a 1-year follow-up. Addiction. 2015; 110(7):1160-8. doi: 10.1111/add.12917.

21. Manzoli L, Flacco ME, Ferrante M, La Vecchia C, Siliquini R, Ricciardi W, Marzuillo C, Villari P, Fiore M; ISLESE Working Group. Cohort study of electronic cigarette use: effectiveness and safety at 24 months. Tob Control. 2017; 26(3):284-292. doi: 10.1136/tobaccocontrol-2015-052822.

Table 1. Characteristics of exclusive electronic cigarette (EC) users and dual users.

\begin{tabular}{|c|c|c|c|c|}
\hline & $\begin{array}{l}\text { Exclusive EC } \\
\text { users (vapers) }\end{array}$ & Dual users & OR $(95 \% \mathrm{CI})$ & p-value \\
\hline $\mathbf{N}$ & 2836 & 353 & & \\
\hline Age (years) & $39.5(10.2)$ & $37.3(10.6)$ & $1.02(1.01-1.03)$ & 0.000 \\
\hline $\operatorname{Sex}(M / W) \%$ & $73 / 27$ & $65 / 35$ & $1.46(1.15-1.85)$ & 0.002 \\
\hline $\begin{array}{l}\text { Duration of EC use } \\
\text { (months) }\end{array}$ & $10.8(4.2)$ & $9.2(4.8)$ & $1.08(1.05-1.11)$ & 0.000 \\
\hline $\begin{array}{l}\text { Frequency of EC } \\
\text { use }(\%) \quad \mathrm{N}=3179\end{array}$ & & & $1.22(1.05-1.41)$ & 0.000 \\
\hline Not every day $n=72$ & 1.6 & 6.3 & & \\
\hline $\begin{array}{l}\text { Every day, } \\
\text { sometimes, n=248 }\end{array}$ & 7.4 & 10.8 & & \\
\hline $\begin{array}{l}\text { Every day, often, } \\
n=1412\end{array}$ & 45.5 & 35.9 & & \\
\hline $\begin{array}{l}\text { Every day, very } \\
\text { often, } n=1447\end{array}$ & 45.3 & 47.0 & & \\
\hline $\begin{array}{l}\text { Check when leaving } \\
\text { home }(\%) \\
\mathrm{N}=3189\end{array}$ & & & $1.16(1.05-1.29)$ & 0.005 \\
\hline Never, $n=37$ & 1.0 & 2.8 & & \\
\hline Rarely, $n=135$ & 4.1 & 5.7 & & \\
\hline Often, $n=451$ & 14.1 & 14.4 & & \\
\hline Very often, $n=238$ & 7.2 & 9.3 & & \\
\hline Always, n=2326 & 73.6 & 67.7 & & \\
\hline $\begin{array}{l}\text { E-liquid nicotine } \\
\text { content }(\mathbf{m g} / \mathbf{m L}, \%) \\
\mathrm{N}=3189\end{array}$ & & & $0.79(0.71-0.87)$ & 0.000 \\
\hline
\end{tabular}




\begin{tabular}{|c|c|c|c|c|}
\hline $1-6, n=1401$ & 46.0 & 27.5 & & \\
\hline $7-12, n=1057$ & 37.3 & 40.8 & & \\
\hline $13-19, n=437$ & 11.7 & 30.0 & & \\
\hline No nicotine, $\mathrm{n}=150$ & 5.1 & 1.7 & & \\
\hline $\begin{array}{l}\text { Amount of nicotine } \\
(\mathrm{mg}) \text { from EC/day }\end{array}$ & $28(16.7)$ & $30.6(18.7)$ & $0.992(0.98-0.99)$ & 0.008 \\
\hline $\begin{array}{l}\text { Nicotine }(\mathbf{m g}) \text { from } \\
\text { cigarettes/day, } \\
\mathrm{N}=352\end{array}$ & & $11.7(9.6)$ & & \\
\hline $\begin{array}{l}\text { Total nicotine } \\
\text { intake /day (mg) }\end{array}$ & $28.0(16.7)$ & $40.9(19.4)$ & $0.965(0.960-0.971)$ & 0.000 \\
\hline $\begin{array}{l}\text { Previous quit } \\
\text { attempt }(\%) \mathrm{N}=3189\end{array}$ & & & $0.63(0.50-0.79)$ & 0.000 \\
\hline Yes, $n=1067$ & 32.3 & 43.1 & & \\
\hline No, $n=2122$ & 67.7 & 56.9 & & \\
\hline $\begin{array}{l}\text { Fagerström Test for } \\
\text { EC dependence, } \\
\text { total score }\end{array}$ & $3.82(2.05)$ & $3.41(1.96)$ & $1.11(1.05-1.17)$ & 0.000 \\
\hline
\end{tabular}

Data are means and (SD) if otherwise not indicated. 
Table 2. Variables in the final model of backward elimination stepwise logistic regression. EC: electronic cigarette. aOR: adjusted odds ratio. Coding: exclusive EC users: 0, dual users 1.

\begin{tabular}{lcccccc}
\hline & Estimate & $\begin{array}{c}\text { Standard } \\
\text { error }\end{array}$ & $\begin{array}{c}\text { Wald } \\
\text { statistic }\end{array}$ & aOR & $\begin{array}{c}\text { 95\% } \\
\text { Confidence } \\
\text { Interval }\end{array}$ & p value \\
\hline $\begin{array}{l}\text { Amount of } \\
\text { nicotine from } \\
\text { EC/day (mg) }\end{array}$ & -2.144 & 0.263 & 66.497 & 0.117 & $\begin{array}{c}0.070 \text { to } \\
0.196\end{array}$ & $<0.001$ \\
$\begin{array}{l}\text { Total nicotine } \\
\text { intake/day (mg) }\end{array}$ & 2.138 & 0.259 & 68.228 & 8.483 & $\begin{array}{c}5.107 \text { to } \\
14.088\end{array}$ & $<0.001$ \\
& & & & & & \\
$\begin{array}{l}\text { Duration of EC } \\
\text { use (months) }\end{array}$ & -0.312 & 0.136 & 5.277 & 0.732 & 0.561 to & 0.022 \\
\hline
\end{tabular}

